\title{
Research on Sports Tourism to Regional Economic Development from the Perspective of Ecotourism
}

\author{
Fan Zhang \\ Department of Police Skills and Tactics, Nanjing Forest Police College \\ Sports Science postdoctoral programme, Nanjing Normal University \\ Nanjing 210023, China \\ zhangfan@nfpc.edu.cn
}

\begin{abstract}
Sports have occupied an important position in the modern life style; while giving people healthy body, it also drives the consumption growth of other sports-related industries. Sports tourism is an example of boosting regional economic development. People will buy various outdoor equipment related to sports during sports tourism. The outdoor products needed for sports tourism can be marketed through physical and non physical products, which is conducive to ecological improvement and can effectively promote the development of local economy. This paper studies the problems of sports resources integration and development in process of sports tourism development from the perspective of new ecotourism by means of literature, expert interviews and questionnaires, and puts forward corresponding strategies for current influencing factors in order to achieve the coordinated development of ecotourism with sports tourism.
\end{abstract}

Keywords-ecotourism; sports tourism; regional economic development

\section{INTRODUCTION}

At present, with the deep understanding of sports function, sports have become an important part of modern amateur life, which can ease the pressure of modern fast-paced life and adjust psychological and physiological balance. At the same time, there also contains tremendous business opportunities. As everyone knows, sport has been more important in China's gross national product and become a strong stimulant to promote social and economic development. Sports tourism market occupies an important share in sports industry; it is of great significance to enrich tourism product system, expand consumption space, activate sports resources, realize the deep integration of national fitness and national health, and expand new space for regional economic development.

\section{CONNOTATION OF ECOTOURISM AND SPORTS TOURISM}

Eco-tourism is a kind of tourism that takes the characteristic ecological environment as the main landscape; it is the tourism mode that relies on the good natural ecological environment and unique humanistic ecological system, carries out the ecological experience, ecological education, ecological cognition and

This work was supported in part by the Project of China Postdoctora Science Foundation under Grant 2017M611849, in part by the Project of the Fundamental Research Funds for the Central Universities under Grant LGZD201805, in part by the 13th Five-Year plan project of Jiangsu Education Science under Grant C-c/2018/01/11, in part by Jiangsu Qing Lan Project under Grant 2017, and in part by Pre-research project of Nanjing Forest police College under Grant LGY201603, and in part by Nanjing Forest police College Teaching Reform Project under Grant ZD18104. obtains the psychosomatic pleasure for people to view, travel and explore in the ecological environment, enjoy a fresh, relaxed and comfortable atmosphere of harmony between nature and human beings, which can enhance health, cultivate sentiment, enjoy natural and cultural heritage, receive environmental education and promote the healthy operation of natural ecosystem [3]. Like other leisure tourism, sports tourism emphasizes the harmony between man and nature, and strengthens the consciousness of protecting nature. The difference lies in the series of new industrial forms of economic activities, which take sports as the key element, take spot watching, participation experience and sightseeing tours as the main forms to meet health entertainment, tourism and leisure, and provide related products and services to the public. From the perspective of ecotourism, the tourism form combining ecology, sports and tourism helps to expand the types of sports industry, promotes the upgrading and adjustment of sports industrial structure, and promotes the green, ecological and healthy development of regional economy.

\section{PROBLEMS INECO-TOURISM DEVELOPMENT}

China's eco-tourism is restricted by immature factors in all aspects, and there are phenomena of unrestrained, excessive development and management confusion for maximizing economic benefits.

\section{A. Chaotic eco-tourism development}

With the increasing living standard and the relative increase of spare time, the release or decompression of body and mind is now the first choice for holidays. Tourism exactly provides a space-time environment to relieve pressure and release, and it also promotes the vigorous development of tourism; especially, on holiday tours, people like to go to nature to gain the fragrance of soil, listen to the rhythm of mountains and springs, as well as birds singing, and breathe fresh air. Ecotourism is in line with people's psychological expectations and is growing rapidly [1].However, while promoting the development of ecotourism market, it neglects the protection of eco-environment. Some experts and scholars are keen on establishing certification and standards of eco-tourism, and are accustomed to the standardization of text model or frame structure thinking in the hope of standardizing the "chaotic" eco-tourism market. However, due to the differences in natural conditions, regional customs, project characteristics and human environment, the development of ecotourism is characterized by complexity and diversity; and the focus and core elements are varied. Therefore, blindly adopting the standards of foreign developed countries is 
not conducive to the development of eco-tourism in China and guidance of norms. While gaining economic benefits from ecological environment, more importantly, it should use economic income to feed back, cherish and repair the natural environment on which we live so as to realize the harmonious coexistence between man and nature.

\section{B. Lack of management and service awareness}

China's eco-tourism is in the primary stage of development. Resources development in all aspects of ecotourism are restricted by many thresholds; the reason lies in many practical problems e.g. the policies and regulations of government on eco-tourism development, construction, guarantee and inspection are lagging behind and not unified [2]. The development of eco-tourism products lacks theoretical support and practical strategy support from government. Moreover, there is no operational mode for cultivation of eco-tourism talents in colleges and universities, resulting in management problems such as sluggish ideas, lax management, weak sense of service, etc.

In addition, the citizens have not high self-quality and ecological consciousness, and there are many problems such as the destruction of ecological environment, facilities and equipment in nature reserves; some tourists even ride around the neck of Red Army statues to take pictures; it lacks guidance, restraint and education on tourists' irregularities. Therefore, the development of eco-tourism in China is still in the cultivation stage, there are a variety of practical problems. In order to promote and improve the development and perfection of ecotourism market, it is necessary to solve the problems that restrict the development of eco-tourism in accordance with the reality of China's vast territory, different characteristics and varied locations.

\section{PROBLEMS IN SPORTS TOURISM}

As a kind of high-level consumption, sports tourism is not only related to the economic development, but also inevitably restricted by social and technological development. It must have a certain degree of economic guarantee for development of sports tourism; to a certain extent, the amount of funds available determines the depth and breadth of development. At the same time, the purpose and means of development must be in line with the development level of science and technology of local society. However, in terms of the basic guiding ideology of sports tourism development, it is necessary to make full use of the existing sports tourism and fully excavate the potential sports tourism to better meet the growing needs for sports. However, the objective forms of sports tourism are different and varied, and the aspects of manifestation are also varied. The development and utilization of various sports tourism should be based on the basic idea of reflecting economic interests. More importantly, it should realize that the development of sports tourism should have ideal social and economic benefits, which is the basic problem that must be considered in the development.

Field survival is an important part of sports tourism. Especially, field survival has become a fashion in recent years, and has been favored by majority of young and middle-aged consumers; which can help challenge themselves, temper the will and achieve the harmony between man and nature. Developing some scenic spots of sports tourism with high-level, accurate project positioning, exquisite routes can cause strong attraction for sports tourism and outdoor sports enthusiasts, conversely, it is not conducive to developing. Most of outdoor survival is far from residential areas e.g. mountains, jungles, deserts, plateaus and other complex areas; these areas are also part of natural environment; professional sports equipment is needed for it, and these equipment is the added value of sports tourism products.

Therefore, sports tourism makes young and middle-aged outdoor sports enthusiasts away from the noisy city; it is the process of facing beautiful nature, washing and purifying the soul. China has a long history and sports tradition, each region has its own characteristics; there is a huge market potential for increasing the number of sports resources. Driving the sales of physical and non-physical outdoor sports products can promote the development of sports and stimulate sports consumption. Therefore, the extension development for sports resources is an important development method. Low-level duplicated construction not only costs a lot, but also leads to limited choice for sports tourists.

\section{ECOTOURISM PROVIDES RESOURCES FOR SPORTS TOURISM}

China has 10.72 million hectares of lakes and reservoirs, 280 thousand sq.km. of coastal area, 94.91 million hectares of forest, 3.2 million sq.km. of mountains and 955,900 sq.km. of river basins. Good ecological environment provides good natural conditions for the development of sports tourism. The protection of ecological environment also needs the support from economic income generated by the development of sports tourism [3]. The ecological environment is the sum of all external conditions that affect the survival and development of human beings and organisms, e.g. ice and snow, drifting, hiking adventure, grassland eco-tourism areas.

Therefore, the development of sports tourism is inseparable from the regional development environment, which has been widely recognized. The contribution of sports to human beings not only stays in the standard of fitness, but also can promote economic development and improve social environment [3]. Sports tourism is not only the simple tour on mountains and rivers, watching competitions, participating in competitions, but also can promote the development of related industries, such as sports clothing, shoes and caps and other industrial resources development.

This is not only a simple development of internal sports resources, it will also lead to a series of economic income from regional transportation, accommodation and catering. This income can be invested in the repair and renovation of environment in turn. Better environment will attract more tourists and reflect the complementarity of economic benefits on social benefits [4,5]. Sports tourism is an active and healthy activity of human beings. Different from the traditional tourism activities, it is a new choice for modern people to release pressure. The economic income from sports tourism also provides economic guarantee for inheritance and protection of folk customs as well as the protection and development of sports environment; both parties support and promote each other. 


\section{SPORTS TOURISMDEVELOPMENT STRATEGY}

\section{A. Scientifically planning sports tourism resources}

Sports tourism resources are the basis of tourism development, and scientific tourism planning is the premise of correct development. The concept of ecological sports emphasizes the coordinated development of human, sports and nature [6]. China has abundant natural resources. It is necessary to plan sports tourism projects scientifically. It emphasizes taking ecology as the background, following the laws of natural ecology and the current situation of regional economic development, aiming at sustainable development and taking ecology as the basis.

\section{B. Creating investment environment}

A good investment environment is the basis and prerequisite for the rapid development of sports tourism in China. First of all, we should speed up the road construction and road upgrading to tourist attractions, to facilitate tourists to travel, and to create a good investment environment for the development of sports tourism. Secondly, the development of sports tourism needs the government's policy support, formulate positive tourism development policies, create a good policy environment for tourism investment, attract investment by various means, such as shares, contracting, leasing and so on, seek common development, and ultimately realize the development goal of effective utilization of regional sports resources and benefit sharing.

\section{ESTABLISHING A NEW MODE OF DEVELOPMENT "ECOLOGY +} SPORTS + TOURISM" TO PROMOTE REGIONAL ECONOMIC DEVELOPMENT TO A NEW LEVEL

At present, the regional economic development is not closed; it can excavate and develop the economic links within and outside the region to achieve the continuous growth and development of regional economy. Sports events are a kind of special and important cultural tourism resources, which play a special role in regional economic development. By introducing high-level sports events, it has injected new vitality into economic development of Huanglong County of northern Shaanxi Province. The competition items are organically combined with local tourism resources to realize the integration development of sports, culture and tourism, attract more tourists to appreciate unique charm of Loess Plateau, deeply tap the potential of sports in regional economic and social development so as to promote the local sports tourism industry and achieve great development.

International sports brand events have unique effects of wide participation and great influence. Sports activities are not just simple activities, it includes graphic media, digital media, advertisement propaganda and planning, sports clothing, etc. A well-known event involves many related industries and also promotes their economic income. According to individual natural resources advantages, each region realizes the integration development mode of "sports + tourism", promotes the integration of leisure sports culture and national fitness based on unique ecological and cultural resources, realizes the integration of culture, fitness and tourism, and transforms the natural resources into new direction of economic development after the introduction of "sports". It will create a new situation of harmonious development and protection of regional economy and ecological environment.

The government should make full use of the existing sports resources and sports resources with market development prospects, allocate the scarce sports resources to different sports production fully, effectively and rationally so as to realize that tourism promotes consumption, consumption stimulates the economy, economy promotes the social development and social development services mankind. Building a sports tourism brand of "sports + tourism + ecology" is a step of deep integration of tourism, sports and ecology. This new mode of development that combines ecology, sports and tourism not only focuses on protection of ecological environment, but also promotes the development of regional economy. At the same time, it is conducive to improving the policies and regulations of sports tourism industry, driving the upgrading of exhibition industry and structural adjustment, and realizing the harmonious development of regional economy and sports tourism market.

\section{CONCLUSION}

From the perspective of ecology, how to realize the coordinated development of ecological environment protection and sports tourism is the primary threat to the development of sports tourism. The natural ecosystem has its own law of replacement. When the external disturbance exceeds the limit of the ecosystem's self-regulation and self-adaptation, it may lead to the imbalance of ecosystem and the decline of environmental quality. With the development of sports tourism in China, the influx of tourists, the construction of various sports tourism facilities and the development of various sports activities will have an impact on the original ecological environment and damage. Therefore, the development of sports eco-tourism should ensure that the ecological environment is not destroyed on the basis of scientific and rational orderly development, scientific planning of sports functional areas, to focus on eco-fragile areas, environmentally sensitive areas and natural reserves of tourism projects. Only in this way can we achieve the coordinated development of regional social, economic, cultural and ecological environment.

\section{ACKNOWLEDGMENT}

I want to take this chance to thanks to Postdoctoral tutor---Wang Zhu-ying, a full professor of Nanjing Normal University. In the process of composing this paper, she gives me many academic and constructive advices, and helps me to correct my paper. Except these, she also gave me the opportunity to do my teaching practice. At the same time, I would like to appreciate my doctoral adviser, who gives me useful knowledge and information in this paper. He is Wang Chang-sheng. At last, I am very grateful of my dear friends, Yang Hai-cheng, Zhang Hui, who offered me the confidence and discuss with me about my paper. Of course, I do need to thanks my tennis friend, Jiang Qin-hua, Zhou Ai-ming, Shi Xiang-qun, et al, my mother, He Zu-ying, my father, Zhang Ben-yong, because of their warm care I can grow up well. 


\section{REFERENCES}

[1] LIU Xiaoming, "Research on Sports Tourism Industry in China in the Light of Industrial Convergence,” Economic Geography, vol. 34, pp. 187-192, June 2016. (In Chinese).

[2] LIU Shaoying, "Research on Ecological Strategy Choice and Sustainable Development of Sports Tourism Industry in Western Region of China,” China sport science and technology, vol. 41, pp. 3-5, January 2005. (In Chinese).

[3] Chen Hao, Ren Yuyong, Wang Li, et al., "Sustainable Development of Ecological Sports Tourism: A Case Study of the Beijing-Hangzhou Grand Canal,’Journal of Beijing Sports University, vol. 38, pp. 26-32, April 2015. (In Chinese).
[4] Xu Liang, "Research on the Development Strategy of Sports Tourism in Qinba Mountains under the Background of Western Ecological Environment Construction,” Journal of Beijing Sports University, vol. 31, pp. 1475-1478, November 2008. (In Chinese).

[5] TAO Ping, "Development of Circular Economy of Rural Sports Tourism:Based on the Perspective of Low Carbon Ecological,” Journal of Shenyang Sport University, vol. 33, pp. 64-67, May 2014. (In Chinese).

[6] Zhou Cheng, Jinchuan, Zhao Biao, et al., "The provincial difference of coupling coordinative development of regional economy-ecologytourism," Journal of Arid Land Resources and Environment, vol. 30, pp. 203-208, September 2016. (In Chinese). 